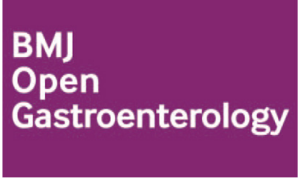

\title{
Cost-effectiveness of surveillance with CT colonography after resection of colorectal cancer
}

\author{
Karen M Kuntz (D) , ${ }^{1}$ Jonah Popp, ${ }^{2}$ J Robert Beck, ${ }^{3}$ Ann G Zauber, ${ }^{4}$ \\ David S Weinberg ${ }^{5}$
}

To cite: Kuntz KM, Popp J, Beck JR, et al. Costeffectiveness of surveillance with CT colonography after resection of colorectal cancer. BMJ Open Gastro 2020;7:e000450. doi:10.1136/ bmjgast-2020-000450

- Additional material is published online only. To view please visit the journal online (http://dx.doi.org/10.1136/ bmjgast-2020-000450).

Received 21 May 2020 Revised 3 July 2020 Accepted 9 July 2020

Check for updates

\section{(c) Author(s) (or their} employer(s)) 2020. Re-use permitted under CC BY-NC. No commercial re-use. See rights and permissions. Published by BMJ.

${ }^{1}$ Division of Health Policy and Management, School of Public Health, University of Minnesota, Minneapolis, Minnesota, USA

${ }^{2}$ Department of Health Services, Policy \& Practice, School of Public Health, Brown University, Providence, Rhode Island, USA

${ }^{3}$ Cancer Prevention and Control Program, Fox Chase Cancer Center, Philadelphia, Pennsylvania, USA ${ }^{4}$ Department of Epidemiology and Biostatistics, Memorial Sloan-Kettering Cancer Center, New York, New York, USA ${ }^{5}$ Department of Medicine, Fox Chase Cancer Center, Philadelphia, Pennsylvania, USA

Correspondence to Dr Karen M Kuntz; kmkuntz@umn.edu

\section{ABSTRACT}

Objective Surveillance following colorectal cancer (CRC) resection uses optical colonoscopy (OC) to detect intraluminal disease and $\mathrm{CT}$ to detect extracolonic recurrence. CT colonography (CTC) might be an efficient use of resources in this situation because it allows for intraluminal and extraluminal evaluations with one test. Design We developed a simulation model to compare lifetime costs and benefits for a cohort of patients with resected CRC. Standard of care involved annual CT for 3 years and $\mathrm{OC}$ for years 1,4 and every 5 years thereafter. For the CTC-based strategy, we replace $\mathrm{CT}+\mathrm{OC}$ at year 1 with CTC. Patients with lesions greater than $6 \mathrm{~mm}$ detected by CTC underwent OC. Detection of an adenoma $10 \mathrm{~mm}$ or larger was followed by $\mathrm{OC}$ at 1 year, then every 3 years thereafter. Test characteristics and costs for CTC were derived from a clinical study. Medicare costs were used for cancer care costs as well as alternative test costs. We discounted costs and effects at $3 \%$ per year. Results For persons with resected stage III CRC, the standard-of-care strategy was more costly (US\$293) and effective (2.6 averted CRC cases and 1.1 averted cancer deaths per 1000) than the CTC-based strategy, with an incremental cost-effectiveness ratio of US $\$ 55500$ per quality-adjusted life-year gained. Our analysis was most sensitive to the sensitivity of CTC for detecting polyps $10 \mathrm{~mm}$ or larger and assumptions about disease progression.

Conclusion In a simulation model, we found that replacing the standard-of-care approach to postdiagnostic surveillance with a CTC-based strategy is not an efficient use of resources in most situations.

\section{INTRODUCTION}

Colorectal cancer (CRC) is the third most common cancer among both men and women in the USA. ${ }^{1}$ Approximately 115000 Americans are projected to be diagnosed with non-metastatic CRC in 2020 and undergo curative resection of their disease, ${ }^{1}$ with possible adjuvant and neoadjuvant therapy. Regardless of initial treatment(s), these patients face an increased risk of developing colorectal adenomas, second primary cancers and metastatic recurrence over time. Several guidelines exist for multicomponent,
Summary box

What is already known about this subject?

- Patients with colorectal cancer are at increased risk of developing adenomas, second cancers and metastatic recurrence.

- Surveillance at 1 year includes CT to detect extraluminal disease and optical colonoscopy to detect intraluminal disease.

- CT colonography allows for intraluminal and extraluminal evaluations with one test.

What are the new findings?

- Replacing standard-of-care surveillance with a CT colonography-based strategy is not an efficient use of resources in most situations.

- ACT colonography-based surveillance strategy may be cost-effective for older patients or with higher values of CT colonography sensitivity for detecting large polyps.

How might it impact on clinical practice in the foreseeable future?

- Findings from our model suggest that replacing optical colonoscopy and CT with CT colonography at 1 year after resection for older patients with colorectal cancer could be a cost-effective strategy.

postresection surveillance for patients with CRC, ${ }^{2-6}$ although the evidence for which approach is optimal is mixed. ${ }^{7-11}$ Recommended surveillance includes an abdominal/ pelvic CT scan annually for the first 3-5 years after resection-as well as more frequent carcinoembryonic antigen assays that could lead to CT-and endoscopic surveillance for the detection of adenomatous polyps and metachronous cancers.

Because postdiagnostic surveillance 1 year after a CRC resection involves optical colonoscopy (OC) to detect intraluminal disease and abdominal CT to detect extraluminal metastatic disease, CT colonography (CTC) may be an efficient use of resources in this setting because it allows for simultaneous intraluminal and extraluminal evaluation. Weinberg 
and colleagues ${ }^{12}$ conducted a prospective, multicentre study to determine whether CTC, relative to OC (ie, the gold standard approach to identifying CRC polyps and cancer), could effectively identify adenomas and cancers in patients 1 year following CRC resection. They found that the sensitivity of CTC was significantly lower than that of OC; however, it is unclear if the increased efficacy of $\mathrm{OC}$ is worth its increased cost. Beck and colleagues ${ }^{13}$ conducted a short-term analysis of the costs and diagnostic yield from the Weinberg study but did not report health and economic outcomes over patients' lifetimes, as recommended by the Panel on Cost-Effectiveness in Health and Medicine. ${ }^{14}$ Accordingly, we conducted a cost-effectiveness analysis of a CTC-based surveillance strategy for patients with surgically resected CRC using a lifetime time horizon, incorporating data on test characteristics and costs from a clinical study of 231 patients evaluated with CTC and OC 1 year postresection. ${ }^{12}$

\section{METHODS}

\section{Overview}

We developed a state-transition Markov model with annual cycles to simulate the downstream events for patients with resected CRC to evaluate the clinical utility of incorporating CTC as part of postdiagnosis surveillance. In any year, simulated patients could reside in a number of health states: no lesion, small $(1-5 \mathrm{~mm})$, medium $(6-9 \mathrm{~mm})$ or large $(10 \mathrm{~mm}$ or larger) adenoma, hyperplastic polyp only (by size), preclinical cancer (by stage; localised, regional or distant), clinical cancer (by stage), diagnosed metastatic recurrence and dead. Over time adenomas can develop or progress in size, large adenomas can progress to preclinical localised cancer, preclinical cancer can progress in stage or be detected through symptoms and new clinical cancers can result in cancer-related deaths. Patients can also experience metastatic recurrence from their initial CRC-either through symptoms or CT_ and face a cancer-specific mortality risk. A schematic of the model is shown in figure 1.

Primary outcomes were discounted lifetime medical costs, quality-adjusted life years (QALYs) and incremental cost-effectiveness ratios (ICERs). Secondary outcomes were number of lifetime OCs, number of new CRCs and number of CRC-related deaths. Costs were calculated from a US healthcare sector perspective. Both costs and outcomes were assessed over a lifetime time horizon and discounted $3 \%$ per year. ${ }^{14}$

\section{Surveillance strategies}

We compared two surveillance strategies for a hypothetical cohort of 60-year-old patients with resected stage II or stage III CRC based primarily on the American Cancer Society guidelines. ${ }^{5}$ We did not model a differential surveillance strategy for rectal cancer as recommended by some guidelines due to our focus on prevention of metachronous cancers and the assumption that patients with rectal cancer would all receive optimal care and thus have much lower local recurrence rates. ${ }^{6} 15$ The standard-of-care strategy involved an annual CT for 3 years and OC for years 1, 4 and every 5 years thereafter. The comparison strategy involved contrast-enhanced CTC (including the CT examination) at year 1, CT only at years 2 and 3, and OC at year 4 and every 5 years thereafter (CTC-based strategy). Patients with lesions greater than $6 \mathrm{~mm}$ detected by CTC underwent follow-up OC, whereas patients with lesions less than $6 \mathrm{~mm}$ did not undergo follow-up OC as is the CTC practice. ${ }^{16}$ Patients with an adenoma $10 \mathrm{~mm}$ or larger diagnosed by OC, considered high risk, ${ }^{17}$ underwent $\mathrm{OC}$ at 1 year and then every 3 years thereafter. Adenomas $<10 \mathrm{~mm}$ were followed according to the initial schedule (table 1). We assumed surveillance would stop at age 80 and that individuals would be perfectly adherent to the surveillance schedule.

We examined two alternative CTC-based strategies in scenario analyses: a strategy where CT would be performed annually for the first 5 years and thus CTC would be used in year 4 as a single test instead of performing CT and OC separately and a strategy where we assumed that those with non-high-risk findings would get OC every 5 years after the initial OC. A schematic of the strategies is shown in table 1 .

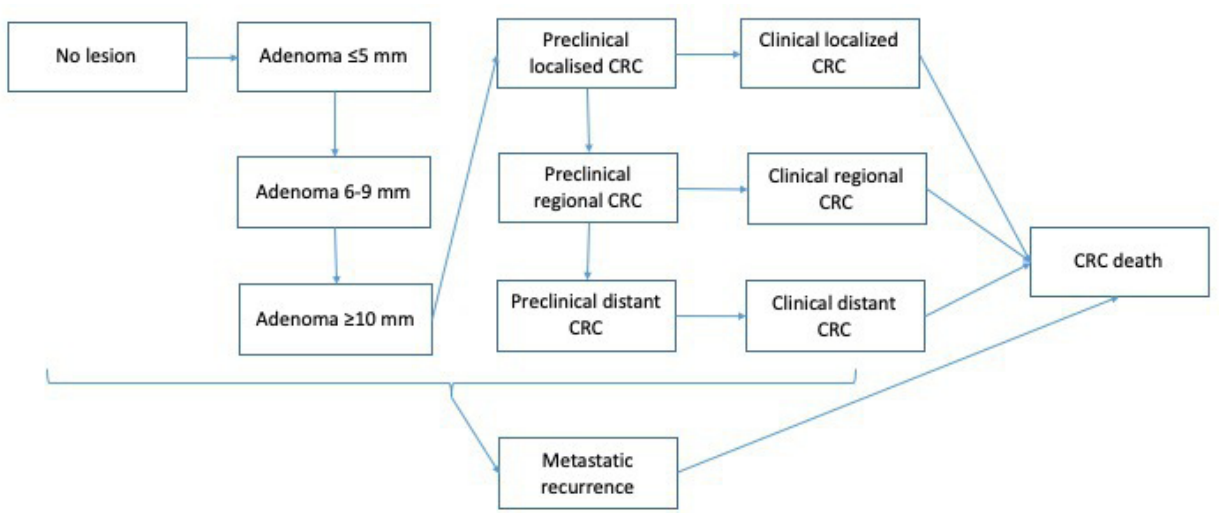

Figure 1 Model diagram showing the intraluminal progression of adenomas to cancer of patients with resected colorectal cancer (CRC). We also allowed for the presence of hyperplastic polyps by size but they could not progress but could lead to colonoscopy if found by CT colonography. 


\begin{tabular}{|c|c|c|c|c|c|c|c|c|c|c|c|}
\hline Year after diagnosis & 1 & 2 & 3 & 4 & 5 & 6 & 9 & 11 & 14 & 16 & 19 \\
\hline \multicolumn{12}{|c|}{ Base-case strategies (assumes 3 years of CT) } \\
\hline Standard of care & $\mathrm{OC}+\mathrm{CT}$ & CT & CT & $\mathrm{OC}$ & & & $\mathrm{OC}$ & & $\mathrm{OC}$ & & $\mathrm{OC}$ \\
\hline CTC-based & CTC & CT & CT & $\mathrm{OC}$ & & & $\mathrm{OC}$ & & $\mathrm{OC}$ & & $\mathrm{OC}$ \\
\hline
\end{tabular}

Scenario analysis strategies (assumes 5 years of $\mathrm{CT}$ )

\begin{tabular}{ccccccccc} 
Standard of care & OC+CT & CT & CT & OC+CT & CT & OC & OC & OC \\
CTC-based & CTC & CT & CT & CTC & CT & OC & OC & OC \\
Scenario analysis strategies (assumes less intensive OC follow-up) & & OC & OC & OC \\
\multicolumn{2}{l}{ Standard of care } & OC+CT & CT & CT & & OC & OC & OC \\
CTC-based & CTC & CT & CT & & OC
\end{tabular}

*Schedule assumes that all test results show no lesion, hyperplastic polyp or adenoma $<10 \mathrm{~mm}$. Persons with adenomas $10 \mathrm{~mm}$ or larger get $\mathrm{OC}$ after 1 year and the 3 yearly thereafter.

CTC, CT colonography; OC, optical colonoscopy.

\section{Clinical data}

Natural history of colorectal disease among patients with resected CRC

The risk of developing an adenoma and the growth rate of each adenoma are greater among patients with resected CRC compared with a screening population. ${ }^{18}$ We used structural assumptions typically used in CRC screening models, ${ }^{19}$ calibrated the model parameters to averagerisk (cancer-free) population targets (eg, adenoma prevalence, CRC incidence) ${ }^{20} 21$ and then increased the transition probabilities by factors in order to match endpoints found in studies of patients following colonoscopic polypectomy of high-risk lesions or resected CRC (online supplementary appendix). ${ }^{22-27}$

We assumed that patients die from their initial CRC by being diagnosed with metastatic recurrence or extramural pelvic disease first and calibrated to the relative survival curves from the Surveillance, Epidemiology, and End Results (SEER) Program, ${ }^{28}$ assuming that the cancer-specific mortality rate among persons with extramural disease was the same as for persons presenting with stage IV CRC. ${ }^{29}$ Annual probabilities of death from other causes were from US life tables. ${ }^{30}$ Disease progression parameters are shown in the online supplementary appendix.

\section{Misclassification of disease at CRC diagnosis}

We estimated the underlying prevalence of residual disease (eg, missed large adenomas) at the time of initial diagnosis so that an OC 1 year after resection would yield the findings reported by Weinberg and colleagues. ${ }^{12}$ The relatively high yield of adenomas observed in that study $(30.8 \%)$ would be from either adenomas missed at initial diagnosis or newly formed adenomas within the first year. We assumed that most adenomas found at 1 year were residual disease, an assumption that is supported by the US Multi-Society Task Force on Colon Cancer. ${ }^{6}$

\section{Test characteristics}

Per-person sensitivity estimates for CTC were determined based on the most advanced lesion found (by size among adenomas, CRC considered more advanced than adenomas, adenomas considered more advanced than hyperplastic polyps, regardless of size) and a CTC was deemed positive if it led to a follow-up OC (table 2). ${ }^{12}$ Specificity was estimated among subjects with no adenomas found by OC. Per-person sensitivity estimates for OC by sizes was based on the literature (table 2). ${ }^{31} 32$ We assumed that the specificity of OC was $100 \%$ because we modelled hyperplastic polyps separately (using the same size-specific sensitivities for hyperplastic polyps).

\section{Colonoscopy-specific complications}

The probability of perforation was 0.6 per 1000 individuals and given a perforation the risk of death was $5.2 \%$, based on a population-based study of colonoscopies performed between 1991 and 1998. ${ }^{33}{ }^{34}$ We also modelled non-fatal perforation events and gastrointestinal bleeding or transfusion and assigned a cost and disutility associated with these events. $^{33}$

\section{Quality of life}

To calculate QALYs, each year of life spent in a health state was weighted by value (utility) between 0 and 1 to reflect the health-related quality of life of that state, where 0 represents death and 1 represents perfect health. Utilities for cancer by stage and phase of care were derived from Ness and colleagues ${ }^{35}$ (table 2). We assigned a utility of 0.67 for all individuals until they experienced metastatic recurrence and were assigned the utility associated with distant CRC (0.25). For patients who developed metachronous CRC, we applied a linear index for predicting utilities of joint health states (eg, stage II CRC and metastatic recurrence) ${ }^{36}$ We assigned utility decrements of 0.038 (ie, assuming a utility of 0 for 2 weeks) for colonoscopy-related morbidity events (perforation or gastrointestinal bleeding). ${ }^{37}$

\section{Costs}

The costs of surveillance tests were derived from the study by Weinberg and colleagues (table 2). ${ }^{12} 13$ We used alternative cost estimates of surveillance tests derived 


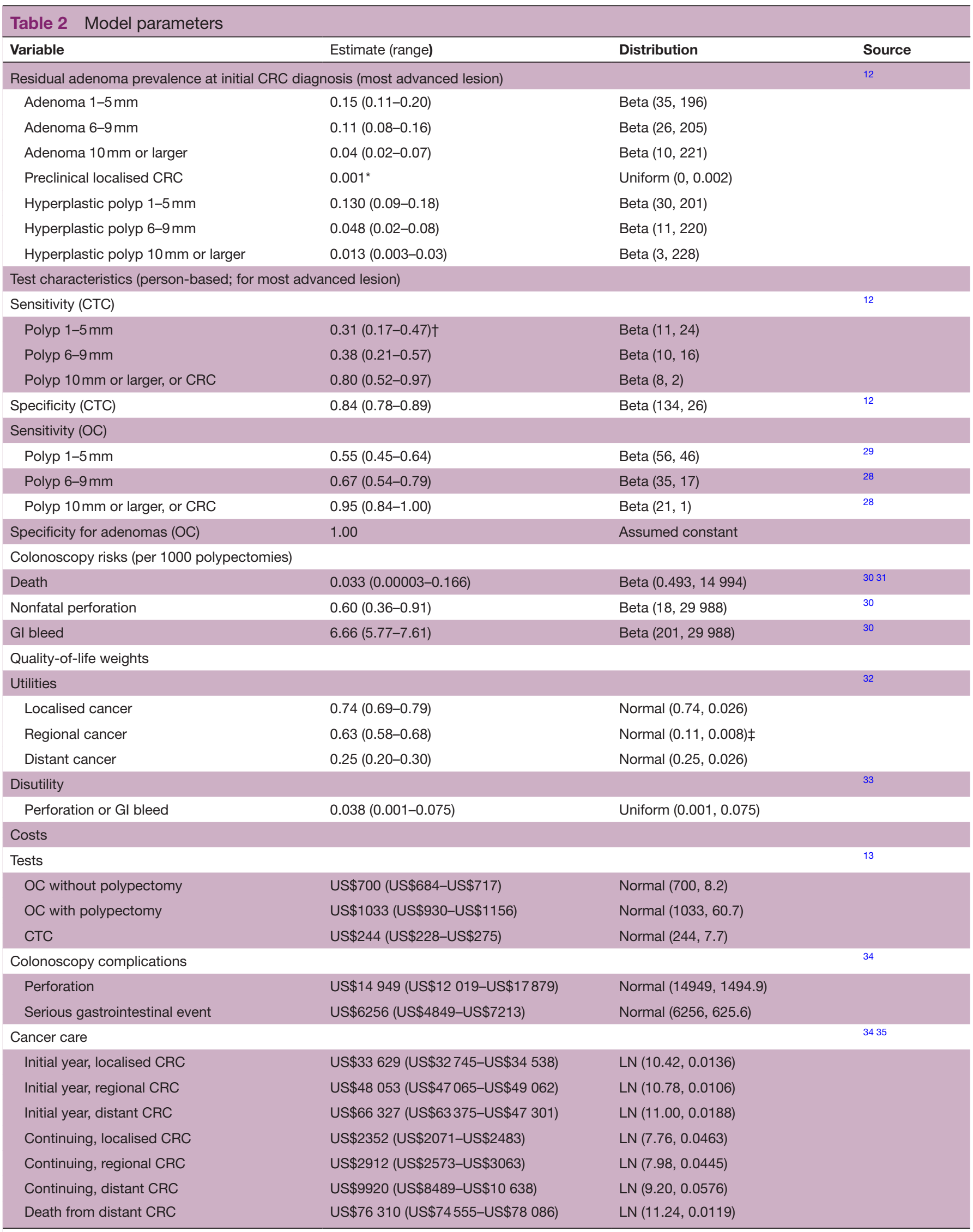

*Assumption.

†Assumed to be 0 in base case.

$\ddagger$ Models the difference between the utility of localised and regional CRC.

CRC, colorectal cancer; CTC, CT colonography; Gl, gastrointestinal; LN, Lognormal; OC, optical colonoscopy. 
from Medicare reimbursement data in sensitivity analysis: US $\$ 259$ for CTC, US\$878 for OC without polypectomy and US $\$ 1291$ for OC with polypectomy. ${ }^{38} 39$ The net costs of CRC-related care were derived from an analysis of CRC cases relative to those of matched controls in the SEERMedicare linked data (ie, these costs represent cancerspecific costs). ${ }^{4041}$ We used phase-specific (ie, last year of life, initial year postdiagnosis and years in between) costs of CRC based on a previous analysis of SEER-Medicare data. All costs were updated to 2019 dollars using the personal consumption expenditure price index.

\section{Analysis}

The model was used to project discounted QALYs and discounted lifetime medical costs for both strategies. We calculated the ICER for the more costly and more effective strategy, defined as the ratio of the difference in cost divided by the differences in QALYs. While cost-effectiveness thresholds between US\$50000 and US\$200 000/QALY are in the range that is considered cost-effective, ${ }^{42} 43$ we used a threshold of US\$100 000/ QALY for our analysis. We performed deterministic and probabilistic sensitivity analyses to test the robustness of our results. The model was programmed in TreeAge Pro (V.2018, TreeAge Software, Williamstown, Massachusetts, USA).

\section{RESULTS}

\section{Base case}

Compared with using CTC as a combined intraluminal/ extraluminal evaluation at 1 year, the standard-of-care strategy increased both lifetime average costs (US\$293 additional discounted dollars) and QALYs (0.0053 QALYs, discounted) for 60-year-old patients with stage III resected CRC (table 3). The ICER of standard of care compared with the CTC-based strategy was US\$55 500/ QALY gained. For patients with resected stage II CRC, the standard-of-care option resulted in an ICER of US $\$ 40$ 200/QALY gained (table 3). Table 4 shows the intermediate outcomes for each strategy. Compared with the CTC-based strategy, the standard-of-care strategy is associated with 789 additional colonoscopies, 2.6 averted CRC
Table 4 Expected outcomes per 1000 individuals with resected stage III colorectal cancer

\begin{tabular}{lccc}
\hline & \multicolumn{2}{l}{ Strategy } & \\
\cline { 2 - 3 } Outcome & CTC-based* & $\begin{array}{l}\text { Standard } \\
\text { of care }\end{array}$ & Difference† \\
\hline $\begin{array}{l}\text { Number of } \\
\text { colonoscopies }\end{array}$ & 3124.1 & 3912.8 & 788.7 \\
$\begin{array}{l}\text { Number of new } \\
\text { CRC cases }\end{array}$ & 12.5 & 9.9 & -2.6 \\
$\begin{array}{l}\text { Number of CRC } \\
\text { deaths } \ddagger\end{array}$ & 318.1 & 317.0 & -1.1 \\
\hline
\end{tabular}

*Assuming 3 yearly CT scans.

†Standard of care minus CTC-based strategy; values could be off due to rounding.

¥Includes cancer deaths associated with the initial cancer diagnosis.

CRC, colorectal cancer; CTC, CT colonography.

cases and 1.1 averted cancer deaths per 1000 persons with resected stage III CRC.

\section{Sensitivity analyses}

In one-way sensitivity analyses, our results were most sensitive to the sensitivity of CTC for detecting adenomas $10 \mathrm{~mm}$ or larger and assumptions about the speed of disease progression (figure 2). If the CTC sensitivity for detecting adenomas $10 \mathrm{~mm}$ or larger was as high as 0.97 , then the ICER for standard of care compared with the CTC-based strategy was US\$210 800/QALY. If we assumed that the annual probabilities of progression through the adenoma states (ie, $1-5$ to $6-9 \mathrm{~mm}, 6-9$ to $10 \mathrm{~mm}$ or larger, $10 \mathrm{~mm}$ or larger to preclinical CRC) was $50 \%$ of our base-case estimates, the ICER for standard of care versus CTC-based strategy was US\$163 400/ QALY. The ICER for standard of care compared with the CTC-based strategy increased to US $\$ 81000 /$ QALY for stage III CRC and US\$60 600/QALY for stage II CRC when we used Medicare costs for the surveillance tests. The ICER for standard of care compared with the CTCbased strategy decreased if we assumed lower adherence with all surveillance testing. However, if we assumed that

\begin{tabular}{|c|c|c|c|c|c|}
\hline Scenario and strategy & Total cost (US\$) & $\begin{array}{l}\text { Health effects } \\
\text { (QALYs) }\end{array}$ & $\begin{array}{l}\text { Incremental } \\
\text { Cost (US\$) }\end{array}$ & $\begin{array}{l}\text { Incremental } \\
\text { QALYs }\end{array}$ & $\begin{array}{l}\text { ICER (US\$/ } \\
\text { QALY) }\end{array}$ \\
\hline \multicolumn{6}{|l|}{ Stage III patients } \\
\hline CTC-based strategy & 121099 & 8.0721 & & & \\
\hline Standard of care & 121392 & 8.0774 & 293 & 0.0053 & 55498 \\
\hline \multicolumn{6}{|l|}{ Stage II patients } \\
\hline CTC-based strategy & 112300 & 9.3684 & & & \\
\hline Standard of care & 112557 & 9.3748 & 257 & 0.0064 & 40193 \\
\hline
\end{tabular}

${ }^{*}$ Costs and effects are generated under the assumption of $100 \%$ systematic adherence to surveillance. A lower systematic adherence would reduce costs and effects proportionally but ICERs would remain unchanged.

CTC, CT colonography; ICER, incremental cost-effectiveness ratio; QALY, quality-adjusted life year. 


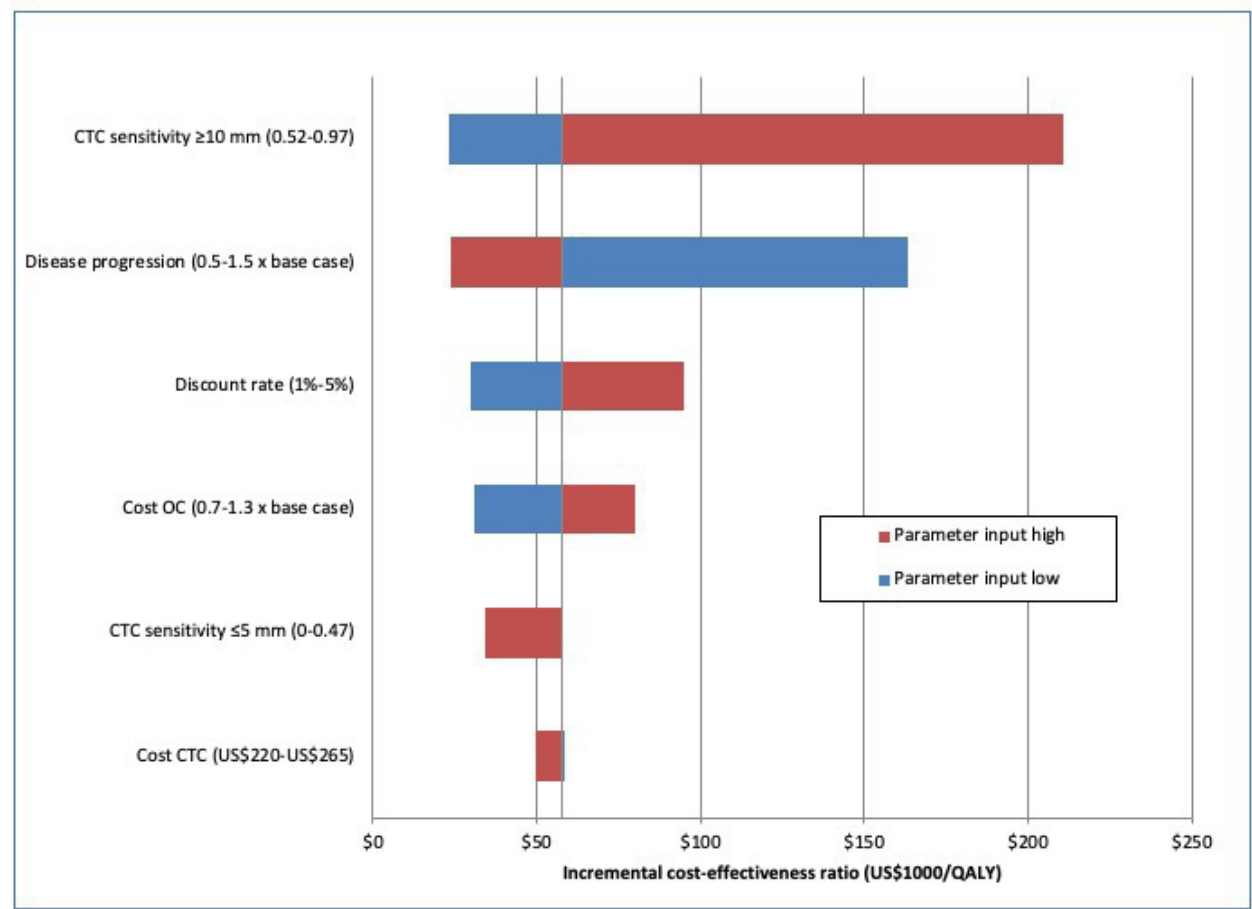

Figure 2 Results from one-way sensitivity analyses. Ranges used to vary each parameter are indicted. Results are for 60 -year-old stage III resected colorectal cancer and represent the incremental cost-effectiveness ratio of standard of care compared with the CT colonography-based strategy.

adherence with CTC was greater than that with $\mathrm{OC}$ at the initial follow-up postresection, there were scenarios for which standard of care would no longer be cost-effective at a cost-effectiveness threshold of US $\$ 100$ 000/QALY. For example, if adherence was $75 \%$ with OC and 99\% with CTC, then the ICER for standard of care would be greater than US\$100 000/QALY (assuming full compliance with OC follow-up if CTC is positive).

\section{Probabilistic sensitivity analysis}

The distributions shown in table 2 represent parameter uncertainty. By running the model for 5000 iterations with random draws from the distributions, we can characterise the overall uncertainty of the cost-effectiveness results. At a cost-effectiveness threshold of US\$100 000/ QALY, the standard-of-care strategy was the most costeffective option in $86 \%$ of the iterations (figure 3 ). The $95 \%$ credible interval for the ICER for standard of care relative to the CTC-based strategy was US\$12 207-US\$207 659/QALY.

\section{Scenario analyses}

We evaluated an alternative CT-based strategy where we assumed that the recommended timing for annual CT scans was 5 years instead of 3 years, as is the case for some guidelines. In this scenario, we assumed that CTC would be used in both years 1 and 4 . The ICER associated with standard of care was lower than in the case of 3 yearly CTs at US $\$ 51$ 100/QALY gained for stage III resected patients. We also evaluated a scenario where we assumed that those with non-high-risk findings would get OC every 5 years instead of the one 3 years after the initial
1 year OC. The ICER of standard of care compared with the CTC-based strategy was US\$24 300/QALY (stage III patients).

We varied the age of the cohort between 50 and 70 years for stage III resected patients. For a cohort of 50-year-old patients, the cost-effectiveness of the standard-of-care strategy compared with the CTC-based strategy was US\$34 500/QALY gained. For a cohort of 70-year-old patients, the ICER increased to US $\$ 106$ 900/QALY.

\section{DISCUSSION}

Recommended surveillance for patients 1 year after CRC resection includes an abdominal/pelvic CT scan to detect distant recurrence and endoscopic surveillance to detect adenomatous polyps or metachronous CRC. Offering patients a single test to accomplish both extraluminal and intraluminal detection may result in both a reduction of testing burden for patients, which could affect adherence to surveillance testing, and an efficient use of resources. We used the methods of decision analysis to determine the differences in lifetime costs and benefits of a strategy that replaces the currently recommended two tests at 1 year $(\mathrm{OC}+\mathrm{CT})$ with a strategy that involves only one initial test (CTC). Health outcomes of new CRC cases detected and cancer-specific deaths were improved with the standard-of-care approach but with an increase in direct medical costs. We sought to determine which strategy was cost-effective for patients with CRC as part of a long-term surveillance protocol. We found that standard-of-care surveillance, when compared with a CTC-based approach, provided a potentially high- value 


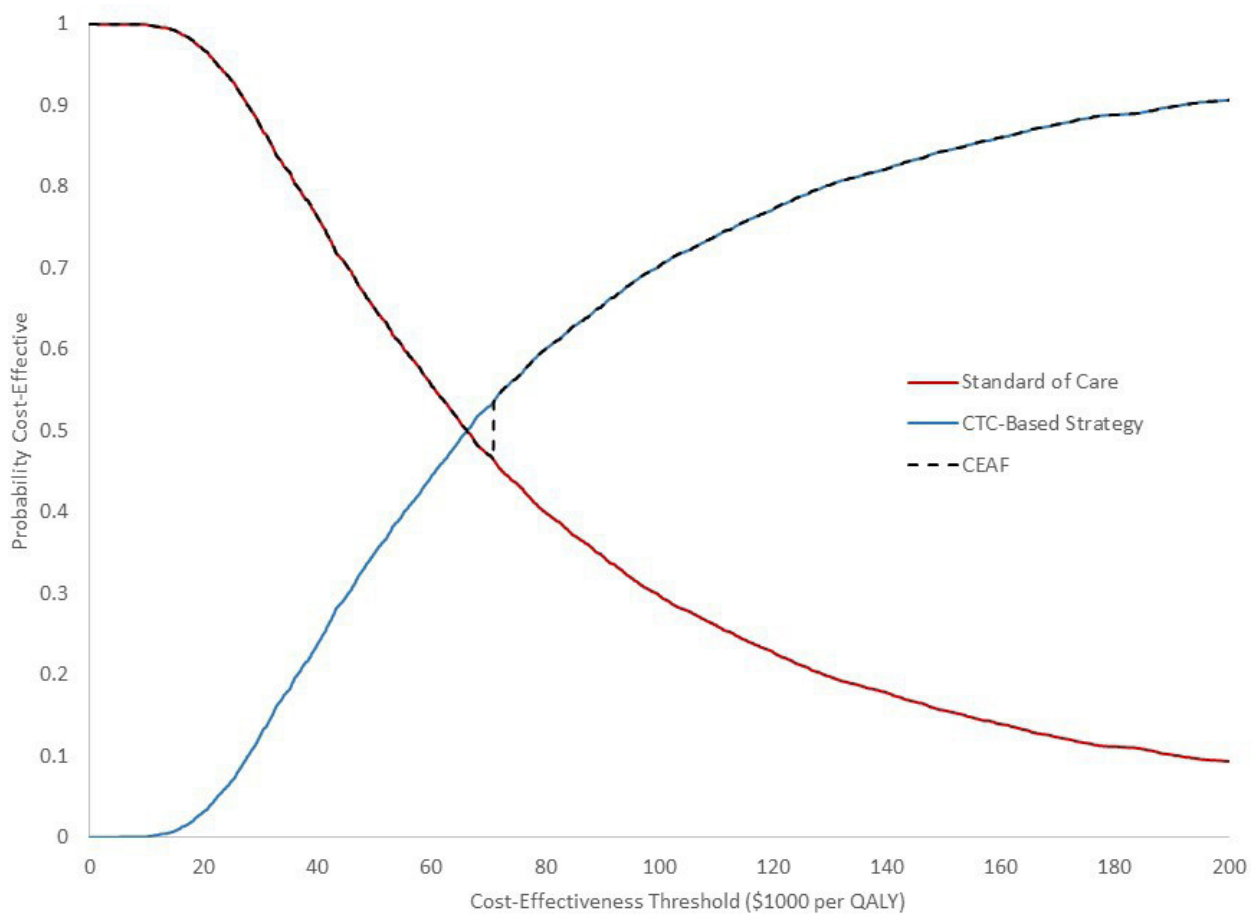

Figure 3 Cost-effectiveness acceptability curve showing the probabilities of standard of care and the CT colonography (CTC)-based strategy being cost-effective in 60-year-old patients with stage III resected colorectal cancer as the costeffectiveness threshold varies. Also shown is the cost-effectiveness acceptability frontier (CEAF) indicating the probability of being cost-effective for the optimal strategy.

approach to managing disease for patients diagnosed with CRC (in other words, is an efficient use of resources). Our results were sensitive to assumptions about the sensitivity of CTC for detecting adenomas $10 \mathrm{~mm}$ or larger and rate of progression through disease states. We also found that standard of care was not cost-effective for older stage III patients (eg, patients over age 69 using a cost-effectiveness threshold of US\$100 000/QALY). Our results incorporated findings from a prospective, multicentre study designed to determine the test characteristics of CTC among patients with CRC 1 year following resection. $^{12}$ The ICER for standard-of-care surveillance compared with a CTC-based strategy was US $\$ 53$ 500/ QALY, which is generally in the range of cost-effectiveness thresholds considered to be cost-effective, and we found an $86 \%$ probability that standard-of-care surveillance is cost-effective.

Our cost-effectiveness results were most sensitive to the sensitivity of CTC for detecting adenomas $10 \mathrm{~mm}$ or larger. Our base-case estimate of 0.80 from the clinical study $^{12}$ had a wide CI, and we found that if that value were as high as 0.90 that standard of care would no long be cost-effective using a cost-effectiveness threshold of US\$100 000/QALY. In addition, the sensitivity that would result in the CT-based strategy being cost-effective would be even lower for older patients (eg, 0.86 for 65-year-old stage III patients). Kim and colleagues ${ }^{44}$ reported a sensitivity of 0.82 for CTC in a postresection setting, which is similar to the estimate we used. Our estimate was lower compared with a meta-analysis of the diagnostic performance of CTC in a screening population (per-person sensitivity of 0.85$).{ }^{45}$ Our analysis was not sensitive to several parameters, including the sensitivity of CTC for polyps smaller than $10 \mathrm{~mm}$ and the risk of death from polypectomy.

We compared two strategies that differed only in the surveillance tests used in the first year following CRC resection. This comparison allowed us to examine the isolated effects related to the use of CTC in this population. Guidelines recommend CT imaging at least yearly for the first 3 to 5 years and for our base-case analysis we assumed CT would be done for the first 3 years, as recommended by the American Society of Clinical Oncology (ASCO) and the European Society for Medical Oncology (ESMO). ${ }^{46}$ When we considered the case of a 5 yearly CT scanning (and thus using CTC at years 1 and 4), the ICER for standard-of-care surveillance compared with a CTC-based strategy was lower (US\$51 100/QALY for patients with stage III resected CRC). Because both strategies had equivalent CT scan usage for the detection of extraluminal metastatic disease, the primary difference between the strategies was the ability to detect underlying adenomas or metachronous CRC at the first year (or first and fourth year) after resection. Because of this, we only found minimal impact when we evaluated a scenario where only a 1 year CT was used. Alternatively, we found a much larger effect on the ICER of standard of care compared with the CTC-based strategy when we evaluated a scenario of decreased intensity of OC (eg, every 5 years after year 1 ). We simulated a lifetime time horizon in order to capture the long-term effects and costs of missing lesions by CTC or overdiagnosis of lesions by OC 
(ie, adenomas that never would have progressed to clinical cancer during a patients' lifetime) at 1 year.

Our results show that patients with postresection CRC could experience a significant reduction in the burden associated with OC under a CTC-based strategy. Of the approximately 100000 patients who undergo CRC resection each year, there would be about 79000 fewer OC procedures performed collectively over their lifetime. The harms associated with a CTC-based strategy, however, would be that an additional 110 patients (of the 100000 ) would die from CRC during their lifetime.

Our study was the first to evaluate the cost-effectiveness of CTC for surveillance in patients after CRC resection. Other studies have evaluated postdiagnosis surveillance strategies. Hassan and colleagues ${ }^{47}$ evaluated the costeffectiveness of performing OC at 1 year compared with no OC and found that 1 year OC was a cost-effective practice. Renehan and colleagues ${ }^{48}$ found intensive follow-up to be economically justified compared with conventional (less intensive) follow-p after curative resection for CRC. ${ }^{48}$

One key limitation to our study was the lack of welldescribed studies to inform estimates of disease progression in patients with postresection CRC. Several studies have been conducted in patients with postresected CRC ${ }^{49}$ with variable results, particularly in terms of the diagnosis of adenomas over time. This is likely due to inconsistent (and often not well reported) scheduling of OC over time. Not all subjects in the studies underwent OC or do so with consistent frequency. The incidence of metachronous cancers would be affected by the degree to which the study cohort was evaluated by OC. For example, more frequent OC would increase the likelihood of detecting an underlying metachronous cancer but would also reduce that chance that the cancer developed in the first place by removing adenomas. We found only one study that we felt provided data sufficiently detailed to use for our calibrations. ${ }^{27}$ Thus, to model disease progression, we used studies among persons found with a high-risk adenoma. ${ }^{22-26}$ In sensitivity analysis, we found that the results were sensitive to assumptions about the transition probabilities associated with disease progression (ie, slower progression favoured the CTC-based strategy).

\section{CONCLUSION}

We conducted a simulation study and found that the standard of care for surveillance after resection for CRC was considered cost-effective by most well-accepted metrics with greater benefits at a greater cost than a CTC-based approach that replaced the first-year CT and OC with a single test, CTC. However, our analysis was sensitive to some key parameters such as the sensitivity of CTC for detecting adenomas $10 \mathrm{~mm}$ or larger. With a sensitivity greater than $91 \%$, greater adherence with CTC compared with OC (eg, $99 \%$ vs $75 \%$ ) and greater patient age (69 years and older), the CTC-based strategy became cost-effective.
Contributors DW is the principal investigator of the study. All authors contributed to the design of the analysis. KMK and JP developed the model and JRB and DW analysed trial data used to inform the model. All authors participated in the discussion and interpretation of results. KMK drafted the manuscript. All authors critically revised the manuscript for intellectual content and approved the final version.

Funding Financial support for this study was provided in part by grants CA155347 and CA006297 from the National Institutes of Health. The funding agreement ensured the authors' independence in designing the study, interpreting the data, writing and publishing the report.

Competing interests None declared.

Patient consent for publication Not required.

Ethics approval All data used to inform the model were derived from the medical literature or summary data from an institutional review board-approved trial.

Provenance and peer review Not commissioned; externally peer reviewed.

Data availability statement No data are available.

Open access This is an open access article distributed in accordance with the Creative Commons Attribution Non Commercial (CC BY-NC 4.0) license, which permits others to distribute, remix, adapt, build upon this work non-commercially, and license their derivative works on different terms, provided the original work is properly cited, appropriate credit is given, any changes made indicated, and the use is non-commercial. See: http://creativecommons.org/licenses/by-nc/4.0/.

ORCID iD

Karen M Kuntz http://orcid.org/0000-0001-6335-7590

\section{REFERENCES}

1 Siegel RL, Miller KD, Goding Sauer A, et al. Colorectal cancer statistics, 2020. CA Cancer J Clin 2020;70:145-64.

2 Benson AB, Venook AP, Bekaii-Saab T, et al. Colon cancer, version 3.2014. J Natl Compr Canc Netw 2014;12:1028-59.

3 Meyerhardt JA, Mangu PB, Flynn PJ, et al. Follow-Up care, surveillance protocol, and secondary prevention measures for survivors of colorectal cancer: American Society of clinical oncology clinical practice guideline endorsement. J Clin Oncol 2013;31:4465-70.

4 Steele SR, Chang GJ, Hendren S, et al. Practice guideline for the surveillance of patients after curative treatment of colon and rectal cancer. Dis Colon Rectum 2015;58:713-25.

5 El-Shami K, Oeffinger KC, Erb NL, et al. American cancer Society colorectal cancer survivorship care guidelines. CA Cancer J Clin 2015;65:427-55.

6 Kahi CJ, Boland CR, Dominitz JA, et al. Colonoscopy surveillance after colorectal cancer resection: recommendations of the US Multi-Society Task force on colorectal cancer. Gastroenterology 2016;150:758-68.

7 Jeffery M, Hickey BE, Hider PN, et al. Follow-Up strategies for patients treated for non-metastatic colorectal cancer. Cochrane Database Syst Rev 2016;3:CD002200.

8 Tjandra JJ, Chan MKY. Follow-Up after curative resection of colorectal cancer: a meta-analysis. Dis Colon Rectum 2007;50:1783-99.

9 Mokhles S, Macbeth F, Farewell V, et al. Meta-Analysis of colorectal cancer follow-up after potentially curative resection. Br J Surg 2016;103:1259-68.

10 Snyder RA, Hu C-Y, Cuddy A, et al. Association between intensity of posttreatment surveillance testing and detection of recurrence in patients with colorectal cancer. JAMA 2018;319:2104-15.

11 Wille-Jørgensen P, Syk I, Smedh K, et al. Effect of more vs less frequent follow-up testing on overall and colorectal cancer-specific mortality in patients with stage II or III colorectal cancer: the COLOFOL randomized clinical trial. JAMA 2018;319:2095-103.

12 Weinberg DS, Pickhardt PJ, Bruining DH, et al. Computed tomography colonography vs colonoscopy for colorectal cancer surveillance after surgery. Gastroenterology 2018;154:927-34.

13 Beck JR, Ross EA, Kuntz KM, et al. Yield and cost-effectiveness of computed tomography colonography versus colonoscopy for post colorectal cancer surveillance. MDM Policy Pract 2018;3:238146831881051.

14 Sanders GD, Neumann PJ, Basu A, et al. Recommendations for conduct, methodological practices, and reporting of costeffectiveness analyses: second panel on cost-effectiveness in health and medicine. JAMA 2016;316:1093-103. 
15 Kapiteijn E, Marijnen CA, Nagtegaal ID, et al. Preoperative radiotherapy combined with total mesorectal excision for resectable rectal cancer. N Engl J Med 2001;345:638-46.

16 Pickhardt PJ, Pooler BD, Mbah I, et al. Colorectal findings at repeat CT colonography screening after initial CT colonography screening negative for polyps larger than $5 \mathrm{~mm}$. Radiology 2017;282:139-48.

17 Gupta S, Lieberman D, Anderson JC, et al. Recommendations for follow-up after colonoscopy and polypectomy: a consensus update by the US Multi-Society Task force on colorectal cancer. Gastroenterology 2020;158:1131-53.

18 Shureiqi I, Cooksley CD, Morris J, et al. Effect of age on risk of second primary colorectal cancer. J Natl Cancer Inst 2001;93:1264-6.

19 Silva-Illanes N, Espinoza M. Critical analysis of Markov models used for the economic evaluation of colorectal cancer screening: a systematic review. Value Health 2018;21:858-73.

20 Rutter CM, Yu O, Miglioretti DL. A hierarchical non-homogenous Poisson model for meta-analysis of adenoma counts. Stat Med 2007;26:98-109.

21 Howlader N, Noone AM. Seer cancer statistics review, 1975-2014. SEER data submission posted to the seer web site, April 2017. Bethesda, MD: National Cancer Institute, 2016. https://seer.cancer/ gov/csr/1975_2014/

22 Martínez ME, Baron JA, Lieberman DA, et al. A pooled analysis of advanced colorectal neoplasia diagnoses after colonoscopic polypectomy. Gastroenterology 2009;136:832-41.

23 Atkin W, Wooldrage K, Brenner A, et al. Adenoma surveillance and colorectal cancer incidence: a retrospective, multicentre, cohort study. Lancet Oncol 2017;18:823-34.

24 Click B, Pinsky PF, Hickey T, et al. Association of colonoscopy adenoma findings with long-term colorectal cancer incidence. JAMA 2018;319:2021-31.

25 Schoen RE, Pinsky PF, Weissfeld JL, et al. Utilization of surveillance colonoscopy in community practice. Gastroenterology 2010;138:73-81.

26 Løberg M, Kalager M, Holme Øyvind, et al. Long-Term colorectalcancer mortality after adenoma removal. $N$ Engl J Med 2014;371:799-807.

27 Kronborg O, Hage E, Deichgraeber E. The remaining colon after radical surgery for colorectal cancer. Diseases of the Colon \& Rectum 1983;26:172-6.

28 Rutter CM, Johnson EA, Feuer EJ, et al. Secular trends in colon and rectal cancer relative survival. J Natl Cancer Inst 2013;105:1806-13.

29 Hassett MJ, Uno H, Cronin AM, et al. Comparing survival after recurrent vs de novo stage IV advanced breast, lung, and colorectal cancer. JNCl Cancer Spectr 2018;2:pky024.

30 Arias E, Heron M, JQ X. United States life tables, 2014. National vital statistics reports. 66. Hyattsville, MD: National Center for Health Statistics, 2017.

31 Zalis ME, Blake MA, Cai W, et al. Diagnostic accuracy of laxativefree computed tomographic colonography for detection of adenomatous polyps in asymptomatic adults: a prospective evaluation. Ann Intern Med 2012;156:692-702.
32 Rex DK, Cutler CS, Lemmel GT, et al. Colonoscopic miss rates of adenomas determined by back-to-back colonoscopies. Gastroenterology 1997;112:24-8.

33 Warren JL, Klabunde CN, Mariotto AB, et al. Adverse events after outpatient colonoscopy in the Medicare population. Ann Intern Med 2009;150:849-57.

34 Gatto NM, Frucht H, Sundararajan V, et al. Risk of perforation after colonoscopy and sigmoidoscopy: a population-based study. J Natl Cancer Inst 2003:95:230-6.

35 Ness RM, Holmes AM, Klein R, et al. Utility valuations for outcome states of colorectal cancer. Am J Gastroenterol 1999;94:1650-7.

36 Basu A, Dale W, Elstein A, et al. A linear index for predicting joint health-states utilities from single health-states utilities. Health Econ 2009;18:403-19.

37 van Hees F, Habbema JDF, Meester RG, et al. Should colorectal cancer screening be considered in elderly persons without previous screening? A cost-effectiveness analysis. Ann Intern Med 2014;160:750-9.

38 Knudsen AB, Lansdorp-Vogelaar I, Rutter CM, et al. CostEffectiveness of computed tomographic colonography screening for colorectal cancer in the Medicare population. J Natl Cancer Inst 2010;102:1238-52.

39 Pyenson B, Pickhardt PJ, Sawhney TG, et al. Medicare cost of colorectal cancer screening: CT colonography vs. optical colonoscopy. Abdom Imaging 2015;40:2966-76.

40 Yabroff KR, Lamont EB, Mariotto A, et al. Cost of care for elderly cancer patients in the United States. J Natl Cancer Inst 2008;100:630-41.

41 Lansdorp-Vogelaar I, Kuntz KM, Knudsen AB, et al. Stool DNA testing to screen for colorectal cancer in the Medicare population: a cost-effectiveness analysis. Ann Intern Med 2010;153:368-77.

42 Neumann PJ, Cohen JT, Weinstein MC. Updating cost-effectiveness-the curious resilience of the $\$ 50,000-$ per-QALY threshold. N Engl J Med 2014;371:796-7.

43 Braithwaite RS, Meltzer DO, King JT, et al. What does the value of modern medicine say about the $\$ 50,000$ per quality-adjusted lifeyear decision rule? Med Care 2008;46:349-56.

$44 \mathrm{Kim} \mathrm{HJ}$, Park SH, Pickhardt PJ, et al. Ct colonography for combined colonic and extracolonic surveillance after curative resection of colorectal cancer. Radiology 2010;257:697-704.

45 Mulhall BP, Veerappan GR, Jackson JL. Meta-Analysis: computed tomographic colonography. Ann Intern Med 2005;142:635-50.

46 Gage MM, Hueman MT. Colorectal cancer surveillance: what is the optimal frequency of follow-up and which tools best predict recurrence? Curr Colorectal Cancer Rep 2017;13:316-24.

47 Hassan C, Pickhardt PJ, Zullo A, et al. Cost-Effectiveness of early colonoscopy surveillance after cancer resection. Dig Liver Dis 2009;41:881-5

48 Renehan AG, O'Dwyer ST, Whynes DK. Cost effectiveness analysis of intensive versus conventional follow up after curative resection for colorectal cancer. BMJ 2004;328:81.

49 Rex DK, Kahi CJ, Levin B, et al. Guidelines for colonoscopy surveillance after cancer resection: a consensus update by the American cancer Society and the US Multi-Society Task force on colorectal cancer. Gastroenterology 2006;130:1865-71. 